\title{
ASSESSMENT OF THE PERFORMANCE OF PAPAIN BASED GEL IN CARIES REMOVAL FROM PRIMARY TEETH - AN IN VIVO STUDY
}

\author{
Manar M. Soliman* , Noha S. Kabil ${ }^{* *}$ and Reham K. Abou El Fadl ${ }^{* * *}$
}

\begin{abstract}
Statement of problem: Restorative dentistry in children is usually considered traumatic and hard to perform in view of factors such as anxiety and expectation both by children and their parents. The main feature for aversion is the noise of the rotary instrument and anesthesia. Several researchers are seeking replacement of traditional mechanical removal of the carious lesions by alternative methods, such as the chemo-mechanical method of caries removal.

Objective: This in-vivo clinical trial was designed to assess the speed of caries removal from primary teeth using Papain-based gel \& the perceived level of dental anxiety among the treated children.

Materials and methods: 20 children were recruited from the outpatient clinic of Pediatric Dentistry and Dental Public health Department, Faculty of Dentistry, Ain Shams University. Inclusion criteria: Age range from 5 to 8 years and presence of two primary occlusal carious lesions involving dentin only not extending to the pulp. For each patient one carious tooth was treated with the conventional carbide bur, while the other one was treated using Papacarié duo. Clinical evaluation was performed by estimating the time required for complete caries removal using stop watch whereas the children's level of anxiety was assessed based on The Facial Image Scale. Wilcoxon signed-rank test was used to compare between Papacarié Duo and conventional technique. Comparisons between quantitative data measured in the same patients were done using paired t-test.
\end{abstract}

Results: Conventional carbide bur showed a statistically significantly higher mean score of perceived pain than Papacarié Duo. Regarding the speed of caries removal, conventional carbide bur required the least time for complete caries removal where a statistically significant difference was detected between both methods.

Conclusions: Papacarié Duo was found to be less painful but more time consuming than the conventional technique.

* B.D.Sc, Faculty of Dentistry, Ain Shams University

** Assistant Professor of Pediatric Dentistry and Dental Public Health, Faculty of Dentistry, Ain Shams University

*** Lecturer of Pediatric Dentistry and Dental Public Health, Faculty of Dentistry, Ain Shams University 


\section{INTRODUCTION}

According to the World Health Organization, caries is defined as "localized post eruptive, pathological process of external origin involving softening of hard tooth tissue and proceeding to the formation of a cavity." There are various techniques available for caries removal, where hand instruments considered being the most primitive approach. Several drawbacks have been associated with this approach being painful, ineffective and classified as a tedious method for caries removal. ${ }^{2}$ Although the invention of rotary instruments improved the speed of caries removal, the destruction of sound tooth substance was more evident. Hence, as early as the $1950 \mathrm{~s}$, there were attempts to develop a less invasive technique, such as the air-abrasive and ultrasonic techniques, for the purpose of caries removal. ${ }^{3}$ An exceptional concern ought to be given to youngsters as their fear and anxiety during dental procedure are much more prominent than among their elder counterparts. Therefore, the ideal cutting instrument should fulfill certain criteria to satisfy both the operator and the patient. These factors include comfort and ease of use clinically added to the ability to discriminate and remove diseased tissue only. Moreover, it needs to be painless, silent, requiring only minimal pressure for optimal use without generating vibration or heat during the periods of operation. No conventional method at present benefits from all these attributes. Indeed, clinical progress in this field seems, relatively speaking, to be lagging behind in restorative material science and even the theory and rationale of caries treatment. ${ }^{4}$

The traditional method of caries removal and cavity preparation entails the use of the burs, which manifested several drawbacks. Commonly, patients perceive drilling as unpleasant and local anesthesia is also frequently required. ${ }^{5}$ Furthermore, drilling can cause deleterious thermal effect combined with the use of pressure for caries removal, causing pulpal effects. The use of a hand-piece may result in removal of softened, dentin that is only affected rather than infected, resulting in an excessive loss of sound tooth structure. ${ }^{6}$

With the advent of adhesive restorative materials and the attempt of exterminating these disadvantages, there was always a growing demand for procedures or materials that facilitate eradication of caries and the restoration afterwards. The approach of minimal invasive technique cherished a belief, where the widely accepted principle of GV Black 'Extension for Prevention' has been challenged and is now considered an extremely destructive approach, being drastically evolved to "Construction with Conservation". 7

Chemo-mechanical caries removal (CMCR) is an alternative to the treatment of active caries using conventional cavity preparation methods. ${ }^{8} \mathrm{CMCR}$ consists of the dissolution of carious tissue by the application of a natural or synthetic agent, followed by atraumatic mechanical removal. ${ }^{9}$ This method is based on the norms of minimally invasive dentistry, allowing patient comfort and the preservation of healthy dental tissue. ${ }^{10}$

The idea of CMCR was developed in 1970s by Goldman while using sodium hypochlorite $(\mathrm{NaOCl})$ in removing organic materials in the root canals. This chemical has the ability to dissolve carious dentin and since then, the idea of removing caries chemically was borne. ${ }^{11}{ }^{12} \mathrm{NaOCl}$, however, was very unstable and too corrosive in nature when applied on healthy tissue. Hence, they decided to incorporate it into Sorensen's buffer (which contains glycine, sodium chloride $(\mathrm{NaCl})$ and sodium hydroxide $(\mathrm{NaOH}))$ in an attempt to minimize this problem.

In Brazil 2003, formula eacao by Sao Paulo, introduced a papain gel, for the first time, commercially known as Papacarié (a word that means "eating caries") as a patent CMCR agent. Papacarié is a national product; registered and approved by ANVISA in Brazil in 2005..$^{13} 14$

Its main components are papain, chloramine and toluidine blue. Papain is a proteolytic enzyme 
which has bactericidal, bacteriostatic and antiinflammatory characteristics. It is an endoprotein similar to human pepsin, acting as a debriding anti-inflammatory without damaging the healthy tissue. It is extracted from the latex of leaves and fruits of the adult green papaya, Carica papaya and cultivated in tropical regions such as Brazil, India, South Africa, and Hawaii. It is largely used in the food, beverage, and drug industries. ${ }^{14}$

Chloramine is formed during reaction between chlorine and ammonia. Chloramines are amines which contain at least one chlorine atom, which is directly bonded to nitrogen atoms. Chloramines have bactericidal and disinfection properties. ${ }^{6,10}$ Initially, the malachite green was used as the coloring agent, however, after a few studies toluidine blue was found to be highly effective against Streptococcus mutans. It is a photosensitive pigment that fixes into the bacterial membrane. ${ }^{6}$

Papain acts only in infected tissue because infected tissue lack a plasmatic anti protease called Anti-trypsin which inhibits protein digestion. The absence of anti-trypsin in infected tissue allows papain to break the partially degraded collagen molecules, contributing to the degradation and elimination of the fibrin "mantle" formed by carious process. ${ }^{14}$

Papacarié was evaluated in-vitro for cytotoxicity in fibroblasts culture at different concentrations $(2,4$, 6, 8 and 10\%) and was proved to be biocompatible. Beside its low cost, ease of application and prompt action, it possesses an antimicrobial effectiveness combined with atraumatic treatment technique offering a painless procedure without affecting healthy tissues. The formation of a smear layer is not observed after the gel is applied. ${ }^{13} 6$

Subsequently, the aim of the current study was to compare carious dentin excavation using
Papacarié Duo and the conventional mechanical method in terms of the pain perceived by children during caries removal from primary molars and the time required to complete this procedure.

\section{MATERIALS AND METHODS}

Prior to intervention an ethical approval was obtained from the Research Ethics Committee at the Faculty of Dentistry, Ain Shams University on December, 2012. Twenty children were recruited from the outpatient clinic of the Pediatric Dentistry and Dental Public health Department, Faculty of Dentistry, Ain Shams University. Only children whose guardians signed an informed consent were enrolled in the current study.

Male and female children aged 5 to 8 years were selected with the following inclusion criteria: The child should have never been to a dentist before. the absence of systemic health conditions; the presence of at least two deciduous molars with acute, active caries not surpassing $2 / 3$ of the dentin and involving only the occlusal surface (this condition was evaluated using bitewing as well as periapical radiographs), no clinical signs or symptoms of pulp involvement. The following were the exclusion criteria: Systemic health condition, Black class II, III or IV caries, deep carious lesion involving the pulp with clinical signs or symptoms of pulp involvement, teeth near exfoliation. ${ }^{15,16}$

The sample was made up of 20 children, among which 40 primary teeth were treated. For each child, one tooth was included in the study group and one was included in the control group. The teeth in Group 1 (G1) underwent conventional caries removal with a low-speed bur and the teeth in Group 2 (G2) underwent CMCR using Papacarié Duo*.

- G1: Caries was removed using a round steel bur in a slow speed hand-piece ${ }^{* * *}$ under coolant.

\footnotetext{
* Fórmula \& Ação, São Paulo. Brazil

** Unik contra angle connected to Unik airmotor, manufactured by KaVo do Brasil Ind. eCom. Ltda.
} 
- G2: Caries excavated using Papacarié Duo according to the manufacturer's instruction. Carious lesion was covered with Papacarié gel and left undisturbed for 40-60 s. After degradation of collagen, blearing of the gel was noticed demonstrating that the removal process could be started. The gel was then removed gently by scrapping with spoon excavator in pendulum like movement without applying pressure. Additional fresh gel was applied on the excavation site and continued until the gel was no longer cloudy. Gel was removed and the cavity was wiped with moistened cotton pellet and rinsed. The main characteristic of the complete removal of infected dentinal tissue was the vitreous aspect of the cavity. ${ }^{17}$ (Fig2)

Clinically the efficacy of caries removal was evaluated by the visual and tactile criteria as described by Ericson et $\mathrm{al}^{18}$ and Munshi AK et al. ${ }^{19}$ Certain parameters were used to assess the caries free status of dentin including hardness on probing, dentin coloration and the unique sound of unaffected dentin on probing. ${ }^{20,21,22,23}$ The visual criteria included the presence or absence of any discolored dentin (infected or affected dentin) after using each and every of caries removal methods. The tactile criteria included the smooth passage of the explorer and presence or absence of a catch or a "tug-back" sensation. Caries was considered removed and the remaining dentin was affected in nature when the explorer did not stick in dentin and did not give a tug-back sensation. ${ }^{24}$

\section{Clinical evaluation:}

- The time taken for treatment of carious teeth, starting from the application of the gel or the use of mechanical burs until complete caries removal was detected using a digital stopwatch.

- The children's level of anxiety was determined using the Facial Image Scale which comprises a row of five faces ranging from very happy to very unhappy. The scale scored by giving a value of one to the most positive affect face and five to the most negative affect face.

The Facial Image Sale was shown to the children at the end of each treatment session following this question: "If you were this face right now, which one would you be?" The child would then point to the corresponding face that best represented their degree of pain or discomfort indicating their feelings when they were undergoing treatment. ${ }^{25}$ Score was recorded according to the chosen face. After caries removal, all cavities were restored using Glass-ionomer restorative material EQUIA Fil ${ }^{\circledR}$ (GC Corporation) according to the manufacturer's instruction

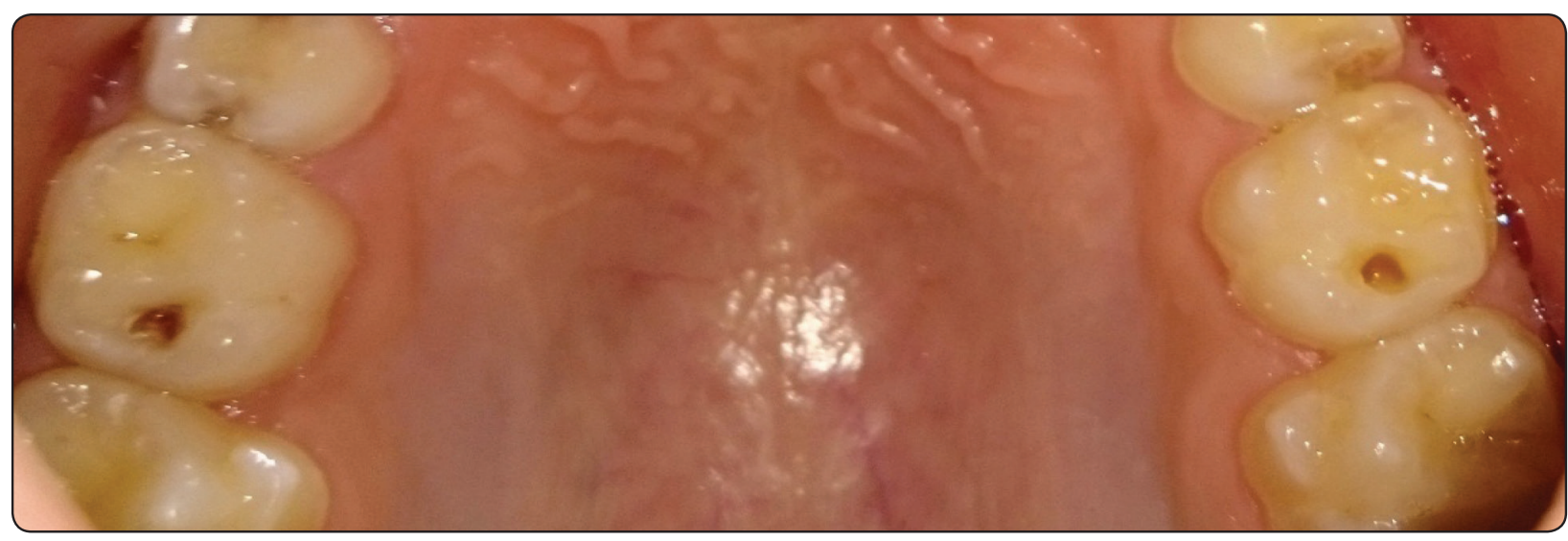

Fig. (1) Pre-operative Photograph Showing Two Carious Lesions in Dentin 


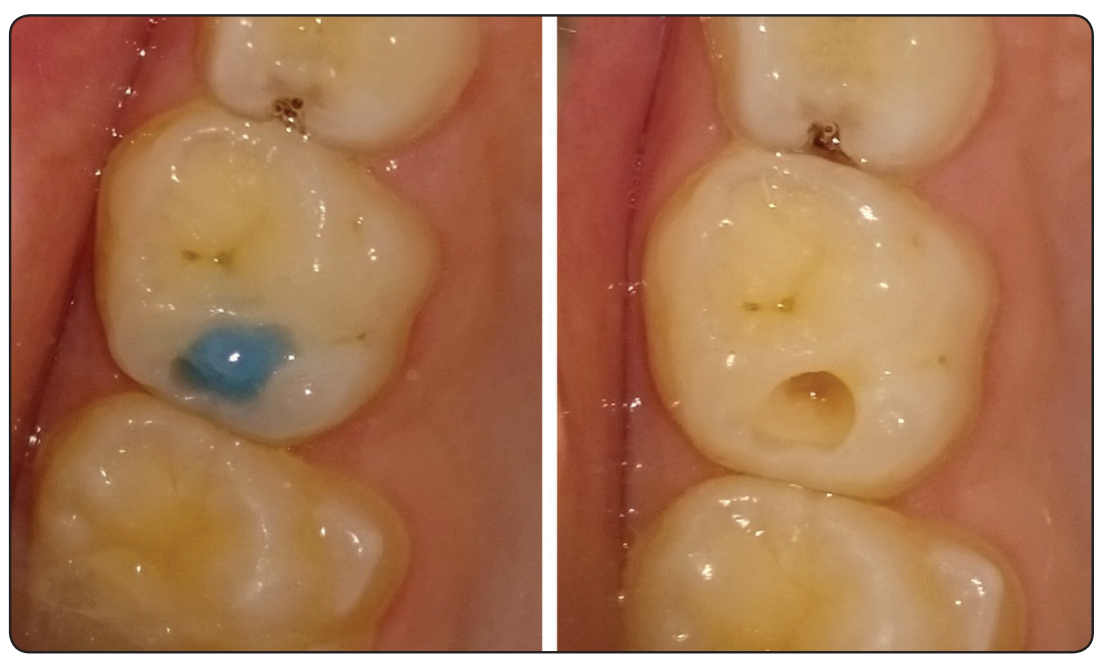

Fig. (2) Application of Papacarié on carious primary molar

\section{Statistical analysis}

Statistical analysis was performed with IBM $^{\circledR}$ SPSS $^{\circledR}$ Statistics Version 20 for Windows, employing the chi-squared test. Quantitative data measured in the same patients were done using paired t-test and Wilcoxon signed-rank test was used to compare between both techniques.

\section{RESULTS}

Twenty children between 5 and 8 years of age participated in the present study with a mean of 6.2 years; 13 of which were females $(65 \%)$ and 7 males $(35 \%)$. The teeth were randomly allocated to two groups based on the treatment method.

Papacarié showed statistically significantly lower mean scores of the perceived pain than conventional carbide bur.

Regarding the required time, conventional bur showed statistically significantly lower mean scores than Papacarié to accomplish the treatment.
TABLE (1) The mean, standard deviation (SD) values after using Papacarié and conventional bur

\begin{tabular}{|c|c|c|c|c|c|}
\hline & \multicolumn{2}{|c|}{ Papacarié group } & \multicolumn{2}{|c|}{ Control group } & \multirow{2}{*}{ P-value } \\
\cline { 2 - 5 } & Mean & SD & Mean & SD & \\
\hline $\begin{array}{c}\text { Facial Image } \\
\text { Scale Score }\end{array}$ & 1.30 & 0.48 & 2.55 & 1.15 & $0.007^{*}$ \\
\hline
\end{tabular}

\section{*: Significant at $P \leq 0.05$}

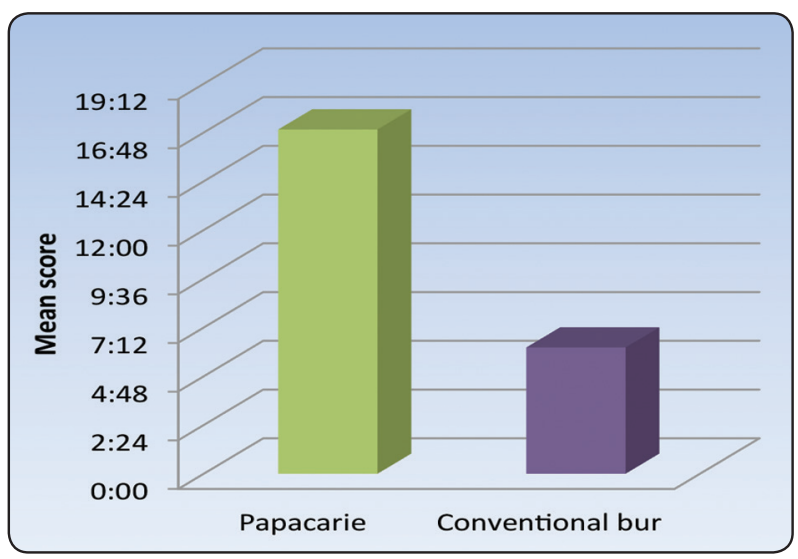

Fig. (3) Mean Time required for caries removal after using Papacarié and Conventional bur

\footnotetext{
${ }^{\circledR}$ IBM Corporation, NY, USA.

${ }^{\circledR}$ SPSS, Inc., an IBM Company.
} 


\section{DISCUSSION}

New methods of caries removal have been always a major objective for dental researchers and practitioners seeking for possible alternatives to the existing conventional modalities especially in the field of pediatric dentistry. This search for alternative systems is aiming to avoid, or at least minimise, the adverse effects produced by drilling instruments has continued for decades ${ }^{26}$. The newer technique of caries removal with chemo-mechanical agents such as Papacarié work on the principles of minimal invasive dentistry, with the merit of diminishing the anxiety and pain anticipated. In the current study a clinical comparison was made between conventional air rotor and CMCR method in terms of perceived pain during treatment and duration of the procedure.

\section{Perceived Dental Anxiety:}

On assessing perceived pain during caries removal using FIS, Papacarié seemed to be the less painful $(1.30 \pm 0.48)$ while conventional rotary instrument caused more pain $(2.55 \pm 1.15)$. The results were similar to those as observed by Gurbuz et al (2004) who concluded that CMCR was a potent method in caries removal provoking less pain and the need for local anesthesia is diminished, thus decreasing fear, anxiety and stress of children.

Rotary instruments are most commonly used method for caries removal even so, pain and discomfort are the main drawbacks associated with the cavity preparation. It is mainly attributed to sensitivity of vital pulp tissues resulting from mechanical stimulus, along with the upshot of high temperatures on the surface cut owing to thermal stimulation. The Papacarié gel is effective only on the denuded fibers in the demineralized dentin, thus painful removal and damage to sound dentin is avoided. ${ }^{27}$

Anusavice and Kinchloe ${ }^{28}$ demonstrated that cutting or removing carious dentin usually elicits little or no sensation, while cutting sound dentin may result in some sort of pain and sensitivity. Similar data have been reported in the study of Zinck et $a l^{29}$ The unpleasant sensation of the vibration associated with the use of Airotor during caries removal makes the treatment more traumatic than CMCR system.

According to Braum et al slight anesthetic effect from the gel has also been observed with the use of CMCR agents. A study was conducted by Fiske et $\mathrm{al}^{27}$ to investigate whether caries removal with $\mathrm{CMCR}$ gel/air abrasion is an alternative to conventional local anesthetics and drills in the treatment of patients. Visual Analogue Scale was used to assess the pain using various methods of caries removal and it was concluded that air abrasion/CMCR gel treatment was a well-accepted and viable alternative to conventional local anesthetics and drill for dental patients.

Papain gel interacts with exposed collagen by the dissolution of dentin minerals through bacteria, rendering the infected dentin softer, enabling its removal with non-cutting instruments without the administration of local anesthesia and burs. ${ }^{30}$ Banerjee et $\mathrm{al}^{4}$ stated that the reason for mild discomfort associated with the use of Papacarié was only attributed to the prolonged time taken to remove the caries. ${ }^{2,31}$

\section{Time Required For Complete Caries Removal:}

The current study revealed that conventional carbide bur required less time for complete caries removal than did Papacarié Duo $(p$-value $<0.001)$ This was in accordance with study conducted by Banerjee et $\mathrm{al}^{4}$ who evaluated five alternative methods of carious dentin excavation and found that conventional method was quickest and CMCR excavation was the slowest out of the five methods. According to the study done by Kakaboura et $\mathrm{al}^{32}$ the reason for increased time taken by CMCR might be due to multiple applications required for caries removal. Bergmann et $\mathrm{al}^{33}$ also reported that time spent for caries removal with CMCR method was 
significantly higher than hand-piece; however, this prolonged operative time did not adversely affect the cooperation of children. ${ }^{34,31}$ On the other hand, Carrillo $\mathrm{CM}^{35}$ showed work time acceptability of Papacarié in pediatric dentistry (4 to $8 \mathrm{~min}$ ).

\section{CONCLUSIONS}

In conclusion, within the limitations of the current study:

1. Papacarié method was found to be the less painful during treatment than did the conventional carbide bur.

2. The time required for complete caries removal was the less favourable using Papacarié as less time was taken when conventional carbide bur was used.

\section{REFERENCES}

1. Sikiri VK. Dental caries. Textbook of Operative Dentistry. 2nd edition. CBS Publishers \& Distributors, p.40-60, (2008).

2. Pandit, I. K., Srivastava, N., Gugnani, N., Gupta, M. \& Verma, L. Various methods of caries removal in children: a comparative clinical study. J. Indian Soc. Pedod. Prev. Dent. 25, 93-6 (2007).

3. Yip, H. K. \& Samaranayake, L. P. Caries removal techniques and instrumentation: a review. Clin. Oral Investig. 2, 148-154 (1998).

4. Banerjee, A., Watson, T. F. \& Kidd, E. A. Dentine caries excavation: a review of current clinical techniques. Br. Dent. J. 188, 476-82 (2000).

5. Ayer, W. A., Domoto, P. K., Gale, E. N., Joy, E. D. \& Melamed, B. G. Overcoming dental fear: strategies for its prevention and management. J. Am. Dent. Assoc. 107, 18-27 (1983).

6. Ganesh, M. \& Parikh, D. Chemomechanical caries removal (CMCR) agents : Review and clinical application in primary teeth. J. Dent. Oral Hyg. 3, 34-45 (2011).

7. Tandon S. Dental caries in early childhood. Textbook of Pedodontics. 1st edition. Paras Publishing, p.178-210, 2003.
8. Tveit, A. B., Espelid, I. \& Skodje, F. Restorative treatment decisions on approximal caries in Norway. Int. Dent. J. 49, 165-72 (1999).

9. Aguirre Aguilar, A. A. et al. [Atraumatic restorative treatment: a dental alternative well-received by children]. Rev. Panam. Salud Publica 31, 148-52 (2012).

10. Bussadori, S. K., Castro, L. C. \& Galvão, A. C. Papain gel: a new chemo-mechanical caries removal agent. J. Clin. Pediatr. Dent. 30, 115-9 (2005).

11. Goldman, M. \& Kronman, J. H. A preliminary report on a chemomechanical means of removing caries. J. Am. Dent. Assoc. 93, 1149-53 (1976).

12. Elkholany NR, Abdelaziz KM, Z. N. Chemo-mechanical method: A valuable alternative for caries removal. J. Minim. Interv. Dent. 9, 248-260 (2002).

13. Lopes, M. C., Mascarini, R. C., da Silva, B. M. C. G., Flório, F. M. \& Basting, R. T. Effect of a papain-based gel for chemomechanical caries removal on dentin shear bond strength. J. Dent. Child. (Chic). 74, 93-7

14. Piva, E. et al. Papain-based gel for biochemical caries removal: influence on microtensile bond strength to dentin. Braz. Oral Res. 22, 364-70 (2008).

15. Matsumoto, S. F. B. et al. Assessment of chemomechanical removal of carious lesions using Papacarie $\mathrm{Duo}^{\mathrm{TM}}$ : randomized longitudinal clinical trial. Indian J. Dent. Res. 24, 488-92 (2013).

16. Kumar, J., Nayak, M., Prasad, K. L. \& Gupta, N. A comparative study of the clinical efficiency of chemomechanical caries removal using Carisolv and Papacarie - a papain gel. Indian journal of dental research : official publication of Indian Society for Dental Research 23, 697 (2012).

17. Corrêa, F. N. P., Rocha, R. D. O., Rodrigues Filho, L. E., Muench, A. \& Rodrigues, C. R. M. D. Chemical versus conventional caries removal techniques in primary teeth: a microhardness study. J. Clin. Pediatr. Dent. 31, 187-92 (2007).

18. Ericson, D. et al. Clinical evaluation of efficacy and safety of a new method for chemo-mechanical removal of caries. A multi-centre study. Caries Res. 33, 171-7 (1999).

19. Munshi, A. K., Hegde, A. M. \& Shetty, P. K. Clinical evaluation of Carisolv in the chemico-mechanical removal of carious dentin. J. Clin. Pediatr. Dent. 26, 49-54 (2001). 
20. Cederlund, A., Lindskog, S. \& Blomlöf, J. Effect of a chemo-mechanical caries removal system (Carisolv) on dentin topography of non-carious dentin. Acta Odontol. Scand. 57, 185-9 (1999).

21. Haak, R., Wicht, M.J. \& Noack, M.J. Does chemomechanical caries removal affect dentine adhesion? Eur. J. Oral Sci. 108, 449-55 (2000).

22. Splieth, C., Rosin, M. \& Gellissen, B. Determination of residual dentine caries after conventional mechanical and chemomechanical caries removal with Carisolv. Clin. Oral Investig. 5, 250-3 (2001).

23. Flückiger, L., Waltimo, T., Stich, H. \& Lussi, A. Comparison of chemomechanical caries removal using Carisolv or conventional hand excavation in deciduous teeth in vitro. J. Dent. 33, 87-90 (2005).

24. Gupta, S., Singh, C., Yeluri, R., Chaudhry, K. \& Munshi, A. K. Clinical and Microbiological Evaluation of the Carious Dentin Before and After Application of Papacarie Gel. J. Clin. Pediatr. Dent. 38, 133-8 (2013).

25. Buchanan, H. \& Niven, N. Validation of a Facial Image Scale to assess child dental anxiety. Int. J. Paediatr. Dent. 12, 47-52 (2002).

26. Lozano-Chourio, M. A., Zambrano, O., González, H. \& Quero, M. Clinical randomized controlled trial of chemomechanical caries removal (Carisolv). Int. J. Paediatr. Dent. 16, 161-7 (2006).

27. Rafique S, Fiske J, Banerjee A. Clinical trial of an air abrasion chemo-mechanical operative procedure for restorative treatment of dental patients. Caries Res, 37(5): 360-364, (2003).
28. Anusavice KJ, Kincheloe JE. Comparison of pain associated with mechanical and chemo mechanical removal of caries. J Dent Res, 66 (11): 1680-3, (1987).

29. Zinck, J. H., McInnes-Ledoux, P., Capdeboscq, C. \& Weinberg, R. Chemomechanical caries removal--a clinical evaluation. J. Oral Rehabil. 15, 23-33 (1988).

30. Aesthetic restoration of deciduous anterior teeth after removal of carious tissue with Papacárie ${ }^{\circledR}$ Motta LJ, Martins MD, Porta KP, Bussadori SK - Indian J Dent Res.

31. Kochhar, G. K., Srivastava, N., Pandit, I. K., Gugnani, N. \& Gupta, M. An evaluation of different caries removal techniques in primary teeth: a comparitive clinical study. J. Clin. Pediatr. Dent. 36, 5-9 (2011).

32. Kakaboura A, Masouras C, Staikou O, Vougiouklakis G. A comparative clinical study on the caries removal method. Quint Int, 34(4): 269-271, (2003).

33. Bergmann J, Leitao J, Kultje C, Bergmann D, Clode MJ. Removing dentinal caries in deciduous teeth with Carisolv: a randomized, controlled prospective study with 6 months follow up comparing chemo-mechanical treatment with drilling. Oral Health Prev Dent, .

34. Kavvadia K, Karagianni V, Polychronopoulou, Papagainnouli L. Primary teeth caries removal using the Carisolv chemo-mechanical method. A clinical trial. Pediatric Dentistry, 26(1): 23-28, (2004).

35. Carrillo CM, Tanaka MH, Cesar MF, Camargo MAF, Juliano Y, Novo NF. Use of papain gel in disabled patients. J Dent Child, 75(3): 222-8, (2008). 